\title{
Integrating Agricultural Pest Biocontrol into Forecasts of Energy Biomass Production.
}

Skevas $^{\mathrm{a}^{*}}$, T., S.M. Swinton ${ }^{\mathrm{a}}$, T.D. Meehan ${ }^{\mathrm{b}}$, T. N. Kim ${ }^{\mathrm{b}}$, C. Gratton ${ }^{\mathrm{b}}$ and A. Egbendewe-

Mondzozo $^{c}$

${ }^{a}$ Department of Agricultural, Food, and Resource Economics and Great Lakes Bioenergy Research Center, Michigan State University, Agriculture Hall, 446 W. Circle Dr., East Lansing MI 48824-1039.

${ }^{\mathrm{b}}$ Department of Entomology, DOE Great Lakes Bioenergy Research Center, University of Wisconsin, Madison, WI 5370.

${ }^{c}$ Center for Agricultural \& Energy Policy Modeling in Africa (CAEMA) and Faculty of Economics and Management Sciences (FASEG), University of Lome, P.O Box: 1515, Lome, Togo.

* Corresponding author. Tel.: +1 517 884-7343; fax: +1 517 432-1800. E-mail address: skevast@ anr.msu.edu

(C) 2014. This manuscript version is made available under the Elsevier user license http://www.elsevier.com/open-access/userlicense/1.0/ 


\begin{abstract}
Biological control of pests is an important ecosystem service in agricultural landscapes as it protects crops and reduces the need for insecticide use. Establishing a sustainable bioenergy industry requires considering the role of biological control in farm decision making. An important question is how biomass supply changes when farmers take into account agricultural pest biocontrol services. A spatially-explicit bioeconomic model of potential biomass supply that incorporates the effect of biological control on crop choice is employed using data from four Wisconsin counties. The results of the study show that integrating agricultural biocontrol into farmers' production technology generally results in biomass from crop residues being supplied more readily (at a lower relative price).
\end{abstract}

Keywords: biological control, bioenergy, bioeconomic model, Wisconsin.

\title{
1. Introduction
}

According to the US Energy Independence and Security Act (EISA), 16 billion gallons of biofuel derived from ethanol made from cellulosic biomass must be produced by 2022. Large quantities of biomass from annual and perennial crops will be required to reach this target. Recent studies indicate that the most cost-effective sources of biomass are crop residues from corn and wheat (Khanna et al., 2011), supplemented at high biomass prices by perennial grasses (EgbendeweMondzozo et al., 2011). These findings, in conjunction with the fact that annual cereal crops 
have grain yield revenue that supplements biomass revenue, imply that the EISA target may be largely met from residues coming from annual crop production.

Increased acreage of annual crops, such as corn, for biofuel production has raised concerns regarding exacerbating environmental externalities such as biodiversity loss, fertilizer and pesticide pollution, greenhouse gas emissions, and soil erosion (Nash, 2007; Searchinger et al., 2008). On the other hand, perennial bioenergy crops such as mixed-species grasslands can provide greater support for a wide variety of ecosystem services (Tilman et al., 2006; Meehan et al., 2011; Meehan et al., 2013) because they require little or no tillage before planting, tend to require less fertilizer than annual crops, and have the ability to maintain or build soil carbon. A valuable ecosystem service in agricultural landscapes is the control of pests by their natural enemies (i.e., biocontrol). Biological pest control can maintain the structure and functionality of agricultural systems (i.e., the interrelations of pests, natural enemies and pesticide use that determine the effectiveness of pest management strategies and optimize growth conditions) and mitigate the need for pesticides (Zhang and Swinton, 2012).

There has been resurgence in incorporating the role of biocontrol in farm decision models. Skevas et al. (2013) incorporate pesticide environmental spillovers in a multi-period model of optimal pesticide use, showing that increased pesticide pressure on natural enemies has a negative impact on output realization. In another recent study, Zhang and Swinton (2012) use a bioeconomic optimization model to assess how predation by natural enemies impacts farm profitability, reporting a high value for biocontrol ecosystem services. Landis et al. (2008) 
examine how an increase in corn acreage in four U.S. states affected biocontrol services in agricultural production. Their findings indicate that an expansion in corn acreage to meet the increasing demand for biofuel production reduced biocontrol services in agricultural landscapes, leading to increased yield losses and pesticide costs (corresponding to an estimated \$58 million per year for the farmers of the four states). Meehan et al. (2012) developed a biocontrol index $(B C I)$ reflecting the ability of natural enemies to control pests in corn and perennial energy crops, and examined changes in $B C I$ in relation to energy crops' expansion. Their results show that increased acreage of annual crops significantly reduced $B C I$ while the expansion of perennial energy crops increased $B C I$, revealing the potential of perennial grasses to mitigate insect damage to plants. Establishment of a sustainable bioenergy industry cannot ignore the impact of the potential change in landscape structure on biocontrol services. This is because loss of biocontrol services provided by natural enemies may result in increases in the use of pesticides and impact the profitability of bioenergy crops and farmers' willingness to adopt these crops.

Among the approaches used to model biomass supply are geographic information systems (GIS) (Graham et al., 2000), non-optimizing cost-benefit ratios (Walsh, 2000; Epplin, 1996), and farm profit maximization models of biomass supply and environmental outcomes (Chen and Khanna, 2012; De La Torre Ugarte et al., 2007; Tembo et al., 2003; Mapemba et al, 2008; Lambert and Middleton, 2010). In a recent study, Egbendewe-Mondzozo et al. (2011) combine elements of these approaches to create a regional spatially-explicit bioeconomic model studying potential cellulosic biomass supply and taking explicitly into account the environmental trade-offs of the changing cropping systems as biomass supply price increases. However, none of these studies integrates the role of pest biocontrol into forecasts of energy biomass production. Our study 
extends the model of Egbendewe-Mondzozo et al. (2011) to incorporate agricultural pest biocontrol in farm decision making, thus accounting for the role of biocontrol agents in changing crop production systems as biomass production increases. As the awareness of the indirect effects of pesticides on beneficial insects is growing, examination of biocontrol effects in farmers' production technology can provide valuable information to researchers and assist policy-makers in designing appropriate bioenergy policies.

The remainder of the article is structured as follows. Section 2 introduces the model specification, followed by the model extensions and calibration procedures. Section 3 presents the definitions and sources of the data used. Results are analyzed in section 4, and conclusions presented in section 5 .

\section{Methodology}

\subsection{Base model of energy biomass production}

The bioeconomic model of Egbendewe-Mondzozo et al. (2011) analyzes the potential for biomass production from cellulosic crops and crop residues. This model comprises a biophysical crop-growth model (EPIC) that simulates crop yields and environmental indicator parameters on the landscape, and a transportation model based on GIS that provides transport distance and time parameters from supply points to a central biorefinery plant site. These two components are fed into a spatially-explicit mathematical programming model which uses market prices and production costs to optimize cropping system choices. More details on the EPIC model and 
transportation cost model, which was applied to Michigan, can be found in EgbendeweMondzozo et al. (2011).

The geographic focus of our study is a four-county region in south-central Wisconsin, USA (Iowa, Columbia, Sauk and Dane counties) and divided into 40 watersheds, as defined by their 10-digit hydrologic unit codes (HUC). Land in each of the watersheds was divided into two categories based on land capability classes (LCC) as defined by USDA natural Resources Conservation Service; one representing high-yielding cropland and a second representing lowyielding cropland (Egbendewe-Mondzozo et al. 2011). The combination of 40 watersheds and two land categories yielded 80 land units (subscript $i$ ) for our analysis. For each of the 80 land units, a representative farmer can select one of 82 different cropping systems $\left(x_{j}\right)$ so that net return over all 80 land units is maximized. The 82 cropping systems are defined in terms of crop rotation, level of fertilization, tillage, and crop residue removal for energy biomass (Table A1). The mathematical expression of the base model is a quadratic program expressed as follows:

$$
\operatorname{Max}_{x_{i j}} \sum_{i=1}^{80} \sum_{j=1}^{82}\left[-c_{j} x_{i j}-\sum_{l=1}^{3} r_{l} o_{l j} x_{i j}+\sum_{s=1}^{15} p_{s}\left(1-\varphi_{s}\right)\left(\rho_{s} x_{i j}-\delta_{s} x_{i j}^{2}\right)\right]
$$

$-\sum_{\mathrm{h}=1}^{9} \mathrm{TC}_{\mathrm{h}}^{\mathrm{t}}$

Subject to

$\sum_{\mathrm{j}}^{82} \mathrm{x}_{\mathrm{ij}} \leq \mathrm{b}_{\mathrm{i}}, \forall \mathrm{i}=1$ to 80 , 


$$
\begin{aligned}
& \sum_{\mathrm{i}=1}^{80} \sum_{\mathrm{j}=1}^{82} \mathrm{e}_{\mathrm{nj}} \mathrm{x}_{\mathrm{ij}} \leq \Gamma_{\mathrm{n}}, \forall \mathrm{n}=1 \text { to } 5 \\
& \sum_{\mathrm{i}=1}^{80} \sum_{\mathrm{j}=1}^{82} \mathrm{a}_{\mathrm{ijh}} \mathrm{x}_{\mathrm{ij}} *\left(\beta+\gamma \mathrm{y}_{\mathrm{i}}+\theta \mathrm{z}_{\mathrm{i}}\right) \leq \mathrm{TC}_{\mathrm{h}}, \forall \mathrm{h}=1 \text { to } 9 \\
& \sum_{\mathrm{h}}^{9} \sum_{\mathrm{i}}^{80} \sum_{\mathrm{j}}^{82} \mathrm{a}_{\mathrm{ijh}}\left(1-\varphi_{\mathrm{h}}\right) \mathrm{x}_{\mathrm{ij}}=\psi
\end{aligned}
$$

The mathematical sets, parameters, and variables used in the model are defined in Table 1. The objective function (1) contains four expressions. The first expression $\left(c_{j} x_{i j}\right)$ represents the total variable production costs (excluding insecticide costs) across all cropping systems and land units. The second expression $\left(\sum_{\mathrm{l}=1}^{3} \mathrm{r}_{1} \mathrm{O}_{\mathrm{lj}} \mathrm{x}_{\mathrm{ij}}\right)$ represents the total cost of synthetic fertilizers across cropping systems and sub-watersheds. Expression $\sum_{s=1}^{15} p_{s}\left(1-\varphi_{s}\right)\left(\rho_{s} x_{i j}-\delta_{s} x_{i j}^{2}\right)$ is the total crop product quantity produced from all cropping systems and land units adjusted for storage losses. The term $\rho_{\mathrm{s}} \mathrm{x}_{\mathrm{ij}}-\delta_{\mathrm{s}} \mathrm{x}_{\mathrm{ij}}^{2}$ defines the quadratic output levels obtained by the multiplication of the linear calibrated marginal yield expression $\rho_{\mathrm{s}} \mathrm{x}_{\mathrm{ij}}-\delta_{\mathrm{s}} \mathrm{x}_{\mathrm{ij}}$ by the quantity of land $\mathrm{x}_{\mathrm{ij}}$ allocated to the production of output s. The quadratic output level expression accounts for declining mean crop yield in response to diminishing land quality as the planted area expands (Howitt, 1995). The last expression $\left(\sum_{\mathrm{h}=1}^{9} \mathrm{TC}_{\mathrm{h}}^{\mathrm{t}}\right)$ is the total transportation cost of each biomass type to the refinery plant. Equation (2) represents the 80 land resource constraints. Equation (3) is a set of constraints that enable the creation of limits on permitted environmental output levels and account for the quantity of environmental outputs. Equations (4) and (5) compute transport costs and total biomass quantity, respectively. The term $\left(\beta+\gamma y_{i}+\theta z_{i}\right)$ is the transport cost of one $\mathrm{Mg}$ of biomass to the refinery site. All parameters, sets, and variables used in the model are defined in Table A2. 


\subsection{Integrating insecticide use and agricultural pest biocontrol into the base model}

The base model used to analyze biomass production from crop residues and cellulosic crops is initially extended to integrate insecticide use. This is realized by adding expression $\mathrm{w}_{\mathrm{j}} \mathrm{x}_{\mathrm{ij}}$ in the objective function as follows:

$$
\begin{aligned}
& \operatorname{Max}_{\mathrm{x}_{\mathrm{ij}}} \sum_{\mathrm{i}=1}^{80} \sum_{\mathrm{j}=1}^{82}\left[-\mathrm{c}_{\mathrm{j}} \mathrm{x}_{\mathrm{ij}}-\sum_{\mathrm{l}=1}^{3} \mathrm{r}_{\mathrm{l}} \mathrm{o}_{\mathrm{lj}} \mathrm{x}_{\mathrm{ij}}-w_{j} \mathrm{x}_{\mathrm{ij}}+\sum_{\mathrm{s}=1}^{15} \mathrm{p}_{\mathrm{s}}\left(1-\varphi_{\mathrm{s}}\right)\left(\rho_{\mathrm{s}} \mathrm{x}_{\mathrm{ij}}-\delta_{\mathrm{s}} \mathrm{x}_{\mathrm{ij}}^{2}\right)\right] \\
& -\sum_{\mathrm{h}=1}^{9} \mathrm{TC}_{\mathrm{h}}^{\mathrm{t}}
\end{aligned}
$$

subject to equations (2) through(5), where $\sum_{i=1}^{80} \sum_{j=1}^{82} w_{j} \mathrm{x}_{\mathrm{ij}}$ is the total cost of insecticides across all cropping systems and land units.

Integrating agricultural biocontrol into the extended model is realized by recalculating the cost of insecticides for each cropping system as follows:

$$
\overline{\mathrm{W}_{\mathrm{j}}}=\left(1-B C I_{T_{i j}}\right) * \mathrm{w}_{\mathrm{j}}=\left(1-\left(\mathrm{BCI}_{F_{i j}}+B C I_{S_{i j}}\right)\right) * \mathrm{w}_{\mathrm{j}}
$$

$B C I_{T_{i j}}$ represents the total biocontrol index for each cropping system $j$ in each land unit $i$. The $B C I_{T_{i j}}$ is composed of $B C I_{F_{i j}}$ and $B C I_{S_{i j}}$ that represent the within crop system $B C I$ and surrounding landscape $B C I$, respectively. Equation (7) represents adjusted insecticide costs $\overline{\mathrm{W}}_{\mathrm{J}}$, which takes into account agricultural pest biocontrol. Actual insecticide costs $w_{\mathrm{j}}$ are scaled by the term $\left(1-\left(\mathrm{BCI}_{F_{i j}}+B C I_{S_{i j}}\right)\right)$. This term $(\in[0,1])$ scales $\mathrm{w}_{\mathrm{j}}$ in such a way that insecticide 
cost in cropping systems not favoring the presence of biocontrol agents remains the same or is reduced by a small amount while insecticide cost in cropping systems favoring the presence of biocontrol agents decreases by a larger amount. The representative farmer decides on which cropping system to grow taking into account the impact of each cropping system on biocontrol potential through its effect on insecticide use costs.

The biocontrol indexes used in this study were first introduced by Meehan et al. (2012). The BCI is based on predation of sentinel crop-pest species by natural enemies (including predators and parasitoids (Letourneau et al., 2009)) in two microhabitats where pests occur (within plant canopies and on the ground). Fieldwork to construct the empirical BCI model [Equation (8)] was conducted at 17 study sites across southern Wisconsin and 17 across lower Michigan, during the summers of 2010 and 2013. BCI at each site was measured by the removal rates of corn earworm (Helicoverpa zea) eggs during two field campaigns, one during June and the other in July of each year. A linear mixed-effects model $(\mathrm{N}=34$, pseudo- $\mathrm{R} 2=0.81)$ is used to model $B C I$ as a function of crop type (i.e., corn, soybeans, switchgrass, and diverse grass) and the proportions of the surrounding landscape in grassland (pasture, hayfields, and conservation grasslands) and woodland (deciduous, coniferous and mixed forests) (Table 2). Landscape proportions were computed in a GIS using the Cropland Data Layer from the National Agricultural Statistics Service of the USDA. Table 2 shows that from the field crops, corn is the worst natural enemy habitat while switchgrass is the most favorable crop for natural enemies. Concerning the landscape covers, grassland provides a more favorable natural enemy habitat than forestland. $B C I$ was related to the crop in which the predation assay occurred and the composition of the surrounding landscape using the fixed effects from the mixed-effects model: 


$$
\begin{aligned}
& B C I_{T_{i j}}=B C I_{F_{i j}}+B C I_{S_{i j}}=\left(0.04 C_{i}+0.08 S_{i}+0.42 S W_{i}+0.25 D_{i}\right) \\
& +\left(0.84 G_{i}+0.37 W D_{i}\right)
\end{aligned}
$$

where $C_{i}, S_{i}, S W_{i}$, and $D_{i}$ are the proportions of corn, soybean, switchgrass, and diverse grass, respectively, in the $i$ th land unit. $G_{i}$ and $W D_{i}$ are the proportions of the surrounding landscape in grassland and woodland, respectively. Therefore, $\left(0.04 C_{i}+0.08 S_{i}+0.42 S W_{i}+0.25 D_{i}\right)$ denotes the within crop system $B C I$ while $\left(0.84 G_{i}+0.37 W D_{i}\right)$ represents the surrounding landscape $B C I$. Woodland proportions were calculated as the proportion of forested habitat in the watershed within which a land unit was located; these proportions were independent of crop type. Grassland proportions were calculated as the proportion of perennial grassland in the watershed within which a land unit was located. Figure 1 depicts the landscape proportions per land unit. Woodland and grassland dominate the landscape in the north eastern land units (i.e., Sauk county and parts of Iowa county) while cropland is the dominant land cover in the western and southern land units (i.e., mainly Columbia and Dane counties).

The surrounding landscape effect is included in our model because it affects pest-predator dynamics by providing food resources and overwintering sites to natural enemies (Corbett and Rosenheim, 1996). Through this habitat mechanism, the surrounding landscape affects the interaction between natural enemies and pests that can shape farm-level insecticide use. The surrounding landscape component $\left(B C I_{S_{i j}}\right)$ is exogenous to the bioeconomic model; the producer treats the surrounding landscape (i.e. proportion of grassland and woodland at the watershed 
level) as a resource characteristic, akin to the land quality. On the other hand, the within crop system component $\left(B C I_{F_{i j}}\right)$ is endogenous to the model, as the producer's choice of cropping system affects the level of biocontrol to component crops.

As represented in the model, cropping systems on agricultural land cover entire subwatersheds, so although they affect the biocontrol services of the component crops, they do not affect biocontrol services on neighboring agricultural land.

Conceptually, $B C I$ is increased by the expansion of perennial energy crops (due to crop type and landscape effects) and decreased when annual crops replace perennial grasslands (Meehan et al., 2012). Natural enemies can prevent crop damage and decrease pesticide use and costs by suppressing pest populations (Landis et al., 2008; Skevas et al., 2013). We assume that low presence of biological control agents (e.g., in continuous corn) will not change insecticide cost while high presence of biological controllers (e.g., in mixed perennial crops) will lead to a linear decrease in insecticide cost. The linear specification is a simplification with two justifications. First, recent research (Meehan et al. 2011, 2012) shows that across a seven-state region and across multiple cropping systems, there is a negative linear relationship between BCI and insecticide application. Thus as biological control potential index increases, we see a linear decline in the need to apply insecticide to prevent yield reductions due to insect pests. Second, insecticide expenditures represent a small part of the representative farmer's total variable cost, so any bias from a linear approximation in lieu of a nonlinear function will be very small. We note that the updated BCI used in the study, which incorporated more crop types than the 
Meehan et al., (2012) study, was generated using field studies of one sentinel pest, the corn earworm. However, removal of this one pest is highly correlated with removal of multiple types of crop pests that inhabit a number of crop microhabitats (Werling et al. 2011, Meehan et al. 2012).

In theory, agricultural biocontrol may have both yield-protecting and cost-reducing effects. We focus on the cost-reducing effect because many farmers already use pest control methods, so added yield protection compared to current practice is unlikely whereas cost savings are quite possible. Moreover, the existing agricultural biocontrol literature reports a surprisingly small effect of agricultural biocontrol on yields of non-organic crops (Landis et al., 2008).

\subsection{Measuring the impact of the surrounding landscape on biomass supply}

To measure the impact of the surrounding landscape on biomass supply from different crops, the model that is adjusted for insecticide use and accounts for agricultural biocontrol is run without accounting for the effect of the surrounding landscape on agricultural biocontrol. This is realized by excluding the effect of the surrounding landscape from the $B C I$ equation in (8):

$B C I_{T_{i j}}=B C I_{F_{i j}}=0.04 C_{i}+0.08 S_{i}+0.42 S W_{i}+0.25 D_{i}$

The adjusted insecticide costs equation (7) also changes as following:

$$
\overline{\mathrm{W}_{\mathrm{j}}}=\left(1-B C I_{F_{i j}}\right) * \mathrm{w}_{\mathrm{j}}
$$


The motivation for excluding the surrounding landscape component from our model is to test its relative effect on pest-predator dynamics and as a result on insecticide use and biomass supply from different cropping systems. Omitting the effect of the surrounding landscape when calculating $B C I$ will decrease $B C I$ and cause a smaller decrease in insecticide costs relatively to the models where $B C I$ accounts both for the impact of field cover and surrounding landscape cover on biocontrol agents. This is expected to slightly decrease cropping systems' marginal profit (relatively to the pre-mentioned models) and may lead biomass to require a higher relative price before it is supplied.

\subsection{Bioeconomic model calibration}

The bioeconomic model is calibrated to 2010-2012 crop market prices and land use following positive mathematical programming methods based on linearly-decreasing marginal yields as a function of planted area (Howitt, 1995). Initially a raw linear model is run, showing that only corn and soybeans are grown across the 80 land units. Then a land use constraint is added and the model is calibrated for the actual land use as observed from USDA data. Finally, we run a model including a quadratic production function that accounts for nonlinearity arising from declining yield as production of a given crop expands onto marginal land (i.e., less suitable land). Shadow prices obtained from the calibrated model are used to calculate the coefficients of each of the linear marginal yield functions. The overall calibration error was $13 \%$ which is within the acceptable range for agricultural sector models used for forecasting (Kanellopoulos et al., 2010). More details of the calibration process can be found in Howitt (1995), Kanellopoulos et al. (2010) and Egbendewe-Mondzozo et al. (2011). 


\section{Data}

\subsection{Biophysical crop and environmental yield data}

In this study, EPIC is used to make predictions of biomass yields and environmental outcomes (i.e., soil erosion, phosphorus loss, nitrate loss, nitrous oxide emissions, and soil carbon loss) for each land unit in south central Wisconsin over a 24-year period (1986-2009). The 82 cropping systems simulated in EPIC are defined by their fertilizer level, tillage, crop rotation, and biomass residue removal (Egbendewe-Mondzozo et al., 2011). Total greenhouse gas emission in $\mathrm{CO}_{2-}$ carbon equivalents is computed using nitrous oxide emissions and soil carbon loss. Grain and forage yields from six field crops (i.e., corn grain, soybean, wheat, alfalfa, canola, and corn silage), biomass yields from seven cellulosic bioenergy crops (switchgrass, Miscanthus, native prairie cool-season mix, native prairie warm-season mix, grass mixes with five and six species, and hybrid poplar), and biomass residue yields from two field crops (i.e., corn stover and wheat straw) are included in the model. The within crop system $B C I$ component $B C I_{F_{i j}}$ was measured as a function of only corn, soybeans, switchgrass, and diverse grass. Because EPIC includes crop rotations with additional crops (i.e., wheat, alfalfa, canola, native prairie, miscanthus, and poplar) some assumptions are needed in order to compute the $B C I_{F_{i j}}$. The mapping between the crops used in the $B C I_{F_{i j}}$ calculation and the additional crops of EPIC was based on the level of ecological disturbance to habitat of natural enemies (e.g., tillage or crop harvest) and similarities among the biophysical and physiological characteristics of these crops (e.g., plant size and shape, physiology, and life-history). Wheat is an annual grass and potentially a more suitable natural enemy habitat than corn (Honek, 1991; Bianchi et al., 2007), therefore it was treated as a crop 
between corn and soybeans (i.e., it was assigned the average value between corn and soybeans, 0.06). Alfalfa is a small stature perennial was treated as diverse grass. Canola is a winter annual broadleaf and was treated as soybeans (a summer annual broadleaf). Miscanthus was treated as switchgrass because both are $\mathrm{C} 4$ warm season perennial grasses. Native prairie and grass mixes are perennials and include a variety of plants and were treated as diverse grass. Finally, poplar is a perennial forest cover was treated as woodland. While many of these substitutions are clearly imperfect, they allow test of concept of the $B C I$ effect on biomass supply.

\subsection{Crop production costs, market prices and biomass transport cost data}

Crop production costs are obtained from Lazarus (2012), the USDA National Agricultural Statistics Service (NASS) (2012), and Stein (2012). Transport costs are calculated using geographic information system data and are based on travel time and distance from supply points to demand points. Storage loss for all biomass types (except poplar trees) is accounted in the model using an $8.8 \%$ loss coefficient, corresponding to dry-matter losses for wrapped round bales stored at field edge for 6 months (Brechbill et al., 2011). The values of all these parameters are given in Table 1.

\subsection{Insecticide use data}

Information for computing insecticide costs are obtained from expert opinion ${ }^{1}$, agricultural chemical suppliers in Wisconsin and Michigan, and Lazarus (2012). Entomologists provided

\footnotetext{
${ }^{1}$ Cullen, E., Associate Professor and Extension Specialist, Entomology Department, University of Wisconsin, and C. DiFonzo, Professor, Department of Entomology, Michigan State University, pers. comm. by email.
} 
information on the most important insects for corn, wheat, soybean and alfalfa and the most important insecticide used in each of these crops (Table 3). The most important insects are corn rootworm and European corn borer ECB in corn, grain aphids in wheat, soybean aphids in soybeans, and potato leafhoppers in alfalfa. Most farmers do not apply added insecticide sprays to corn because they plant $B t$ corn that secretes a natural lepidopteran insecticide that controls the two leading insect pests (Fernandez-Cornejo and Wechsler, 2012). By contrast, due to the soybean aphid infestation since 2000, insecticide use in soybean has been rising, and it reached 29\% in Wisconsin in 2012 (USDA, 2014). Wheat is often sprayed for wheat aphid, as is alfalfa for alfalfa leafhopper (USDA, 2014; Lazarus, 2012). Two-thirds of soybean, wheat and alfalfa land in the study zone is not treated with insecticide, so in principle yields of these crops benefit from natural pest control that has not been captured in past bioenergy crop models. In lieu of modeling the revenue-enhancing yield benefits, we conservatively model all three crops as if receiving recommended insecticide applications whose reduction can cut costs.

In general pyrethroids (lambda-cyhalothrin) are used on all field crops for reducing damage caused from aphids. Lambda-cyhalothrin has the trade name Warrior. Prices for Warrior where obtained after contacting agricultural chemical suppliers in Wisconsin and Michigan. Application specific information such as application dosage is obtained from insecticide labels. Total insecticide costs per hectare for each crop system include the cost of active ingredient and the application cost (i.e., mean cost of using either a self-propelled or a pull-type boom sprayer). The latter includes fuel, lubricants, repairs and maintenance, labor, power, overhead costs (interest, insurance, and housing), and implement depreciation (Lazarus, 2012). 
For perennial bioenergy crops, this study assumes no insecticide cost, because at present these crops are rarely cultivated in the study area. However, when these crops become widely cultivated, insects that cause significant crop damage may appear (e.g., Bradshaw et al., 2010). This model could be easily extended to include insecticide costs of perennial crops.

\section{Results and Discussion}

\subsection{Base model}

To evaluate the evolution of biomass supply in response to price, the bioeconomic model is solved with sequentially-increasing delivered-biomass prices while all other prices are held constant. Figure 2 presents the biomass supply and sources as a function of biomass:corn-grain price ratios. The corn-grain price $(\$ 237 / \mathrm{Mg}=\$ 6 /$ bushel) is used as numéraire, since corn is the major crop in the region and thus a familiar benchmark. Corn stover becomes profitable to collect at a minimum delivered biomass:corn-grain price ratio of $0.105(\$ 25 / \mathrm{dry} \mathrm{Mg})$, followed by wheat straw which becomes profitable to collect at a minimum delivered biomass:corn-grain price ratio of 0.131 ( $\$ 31 / \mathrm{dry} \mathrm{Mg})$. Crop residues begin to be supplemented by biomass from grass mixes when the delivered biomass:corn-grain price ratio reaches 0.409 ( $\$ 97 / \mathrm{dry} \mathrm{Mg}$ ). When the delivered biomass:corn-grain price ratio reaches $0.481(\$ 114 / \mathrm{dry} \mathrm{Mg})$, switchgrass enters biomass production. Grass mixes and switchgrass completely replace crop residues when the delivered biomass:corn-grain price ratio reaches 0.63 ( $\$ 149 / \mathrm{dry} \mathrm{Mg})$. 
Figure 3 illustrates how land use changes in response to the sequentially-increasing biomass price. Supplying crop residues for biomass causes farmers to supplant corn for silage and alfalfa with wheat and corn for grain, a substitution that can be expected to have repercussions on the availability of dairy feed. The production of grass mixes at a minimum delivered biomass:corngrain price ratio of 0.409 ( $\$ 97 / \mathrm{dry} \mathrm{Mg})$ does not decrease crop-grain land use. The latter is decreased when switchgrass enters production at a minimum delivered biomass:corn-grain price ratio of 0.481 ( $\$ 114 /$ dry $\mathrm{Mg}$ ). Grass mixes and switchgrass displace all crop-grain production when the delivered biomass:corn-grain price ratio reaches $0.63(\$ 149 / \mathrm{dry} \mathrm{Mg})$.

Figure 4 depicts the percentage change in environmental output levels relative to the baseline of no biomass production, demonstrating the impact of biomass supply activities on the environment. Changes in most of the environmental outputs follow a similar pattern; cropresidue removal increases soil erosion, nitrate loss, phosphorus loss, and soil carbon loss. When annual crops are replaced with perennial crops, all environmental outcomes improve. This is because perennial crops require lower levels of nitrogen fertilization and need no tillage after planting.

Comparing the results of the current model with results from the respective model for Michigan (Egbendewe-Mondzozo et al., 2011), we find that all biomass sources in Wisconsin are supplied at an equal or higher biomass:corn-grain price ratio than in Michigan. This difference can be attributed to the fact that Wisconsin has higher-quality soils, resulting in higher value grain products and higher opportunity cost of replacing grain crops with perennials. Concerning the 
sequence of crop-production systems as biomass price increases, both models show a decrease in land for corn silage and alfalfa as farmers start providing biomass from crop residues. Crop-grain land starts decreasing when farmers begin supplying biomass from switchgrass. Regarding change in environmental outcomes relative to the scenario of no biomass production, both models show an initial increase in damaging environmental outcomes when crop residue supply starts, and a decrease when biomass from perennial energy crops begins to replace biomass from crop residues.

\subsection{Model with insecticide use}

In this scenario, the Wisconsin base model is extended to include constant insecticide costs for the different cropping systems. As before, the extended model is solved by sequentially increasing delivered biomass prices to evaluate the evolution of biomass supply. Corn stover becomes profitable to collect at a minimum delivered biomass:corn-grain price ratio of 0.122 (\$29/dry Mg) instead of 0.105 (\$25/dry Mg), followed by wheat straw, which becomes profitable to collect at a minimum delivered biomass:corn-grain price ratio of 0.135 (\$32/dry $\mathrm{Mg})$ instead of 0.131 (\$31/dry Mg). Biomass supply from perennial crops is mildly sensitive to integrating insecticide costs, but in a different direction in comparison to corn stover and wheat straw. Crop residues begin to be supplemented by biomass from grass mixes when the delivered biomass:corn-grain price ratio reaches 0.405 (\$96/dry Mg) instead of 0.409 (\$97/dry Mg). When the delivered biomass:corn-grain price ratio reaches 0.477 (\$113/dry $\mathrm{Mg}$ ) instead of 0.481 (\$114/dry Mg), switchgrass enters biomass production. Grass mixes and switchgrass completely replace crop residues when the delivered biomass:corn-grain price ratio reaches $0.63(\$ 149 /$ dry $\mathrm{Mg}$ ). Thus, integrating insecticide use into the base model causes an increase in production costs 
across cropping systems with a mixture of annual crops, leading biomass supply from crop residues occurring at a higher relative price and supply from perennial crops at a lower relative price of biomass compared to corn-grain. The inclusion of insecticide cost for annual crops decreases their marginal profit, leading farmers to supply biomass from crop residues at a higher biomass:corn-grain price ratio. Decreased marginal profitability of annual crops triggers farmers to replace them at a lower biomass:corn-grain price ratio with perennial energy crops, since the latter have zero insecticide cost.

\subsection{Model with insecticide use and $B C I$}

When integrating agricultural biocontrol into the model adjusted for insecticide use, corn stover becomes profitable to collect at a minimum delivered biomass:corn-grain price ratio of 0.105 (\$25/dry Mg), instead of 0.122 (\$29/dry Mg) for the model adjusted to include insecticide use. This is followed by wheat straw, which becomes profitable to collect at the same point as in the

previous two models, a minimum delivered biomass:corn-grain price ratio of 0.135 ( $\$ 32 /$ dry $\mathrm{Mg}$ ). Biomass from grass mixes begins to supplement biomass from crop residues when the delivered biomass:corn-grain price ratio reaches 0.405 (\$96/dry Mg). Switchgrass biomass starts to be supplied when the delivered biomass:corn-grain price ratio reaches 0.477 ( $\$ 113 / \mathrm{dry} \mathrm{Mg})$. Grass mixes and switchgrass completely replace crop residues when the delivered biomass:corngrain price ratio reaches $0.63(\$ 149 / \mathrm{dry} \mathrm{Mg})$.

Figure 5 presents the minimum biomass supply price for crop residues and annual crops across the different modeling scenarios. Adding in BCI causes farmers to supply corn stover at a lower biomass:corn-grain price ratio than the model with insecticide use but without $B C I$. Corn stover 
is supplied by cropping systems including a mixture of annual crops, as the model results indicate that corn, alfalfa, wheat, and soybeans are grown in five different cropping systems across the 80 watersheds. Including $B C I$ in the existing modeling framework decreases the expected insecticide cost of cropping systems composed of different annual crops. This causes an increase in the marginal profit of these crops leading to biomass from crop residues to be supplied more readily at a lower biomass:corn-grain price ratio (Figure 5).

\subsection{Model of biomass supply without the surrounding landscape effect}

When ignoring the effect of the surrounding landscape on agricultural biocontrol in the model that accounts for agricultural biocontrol, corn stover becomes profitable to collect at a minimum delivered biomass:corn-grain price ratio of 0.110 (\$26/dry $\mathrm{Mg}$ ) instead of 0.105 (\$25/dry $\mathrm{Mg})$, while biomass from wheat and perennial crops is supplied at the same corn-grain price ratio (Figure 5). The exclusion of the surrounding landscape decreases the marginal profitability of cropping systems that include annual crops (compared to the respective model that accounts for both the within crop system $B C I$ and the surrounding landscape $B C I$ ), leading biomass from corn to be supplied at a higher biomass:corn-grain price ratio. The slight change in biomass supply when ignoring the effect of the surrounding landscape on pest biocontrol may be attributed to the fact that this effect is only watershed specific and does not vary by cropping system. Therefore, what drives the changes in biomass supply is mostly the within crop system $B C I$ component. Ignoring the surrounding landscape effect leads to a decrease in farmer's profitability of around $0.13 \%$ in the model that accounts for agricultural pest biocontrol. This decrease is due to the fact that $B C I$ is decreased leading to an increase in insecticide costs. 


\section{Conclusions}

Natural enemies suppress crop pests thus providing a valuable ecosystem service in agricultural landscapes. Annual crops support lower abundances of natural enemies than do perennial energy grass. Accounting for the role of biocontrol in farm decision-making models of biomass supply can provide a more complete understanding of changed cropping system responses to increases in biomass production. This study integrates agricultural pest biocontrol into a spatially-explicit bioeconomic model of potential cellulosic biomass supply and shows how a representative decision maker adjusts cropping system choices when taking into account the role of agricultural biocontrol in mitigating insecticide costs.

The empirical results indicate that including insecticide cost in biomass supply forecasts will cause biomass from annual-crop residues to be supplied at a higher relative price of biomass while perennial crops are supplied at a lower relative price of biomass compared to corn grain. The supply of crop residues at a higher price is attributed to an increase in production costs across cropping systems with a mixture of annual crops that also causes biomass from perennial energy crops to be supplied at a lower relative price. The integration of agricultural pest biocontrol in the biomass supply model leads biomass from crop residues to be supplied at a lower biomass:corn-grain price ratio. This finding is driven by biocontrol services that increase the marginal profit of mixed annual cropping systems by reducing insecticide costs. Because the biocontrol index $(B C I)$ plays an important role in farm decision making, more research to better measure $B C I$ will enable farmers to choose cropping systems that take advantage of biocontrol 
services and also help policy makers to introduce a sustainable bioenergy industry. Better diffusion of information regarding natural enemies and their ecosystem services can also help farmers to strategically position perennial grasses allowing them to reap the potential benefits of agricultural biocontrol.

As conservatively modeled here, the magnitude of the effect of integrating natural biocontrol into a bioenergy crop supply model is small. The small magnitude results from the decision to model the value of natural biocontrol only through insecticide treatment cost reduction, rather than by the value of crop yield protected by beneficial natural enemies of insect pests. Additional research is needed to more accurately measure yield protection effects as well as underlying predator-prey dynamics affecting pest populations. The conservative current model clearly shows that results can be distorted when omitting the effect of the surrounding landscape on agricultural pest biocontrol. Excluding this effect from biomass supply forecasts will cause biomass from annual crops to be supplied at a higher relative price of biomass. The surrounding landscape provides additional biocontrol services indirectly as source habitats for natural enemies and can further mitigate insecticide cost. Therefore, it should be taken into account when modeling farm-level decisions on energy biomass supply. More research on the potential of pest epidemics following a potential expansion of perennial crops could enrich the current analysis, and provide a better understanding of likely pest-control costs and associated natural biocontrol benefits.

\section{Acknowledgments}


This work was funded by the DOE Great Lakes Bioenergy Research Center (DOE BER Office of Science DE-FC02-07ER64494, DOE BER Office of Science KP1601050, DOE EERE OBP 20469-19145). 


\section{References}

Bianchi, F.J.J.A., Honek A., van der Werf, W., 2007. Changes in agricultural land use can explain population decline in a ladybeetle in the Czech Republic: evidence from a process-based spatially explicit model. Landscape Ecol. 22, 1541-1554.

Bradshaw, J.D., Prasifka, J.R. Steffey, K.L., Gray M.E., 2010. First report of field populations of two potential aphid pests of the bioenergy crop Miscanthus x giganteus. Fla Entomol. 93,135137.

Brechbill, S.C., Tyner, W.E., Ileleji, E.K., 2008. The economics of biomass collection, transportation and supply to Indiana cellulosic and electric utility facilities [accessed on February 25, 2013]; Available from: http://ideas.repec.org/p/pae/wpaper/08-03.html ERS Report, 2013;

Chen, X., Khanna, M., 2012. The market-mediated effects of low carbon fuel policies. AgBioForum 15, 1-17.

Corbett, A., Rosenheim, J.A., 1996. Impact of a natural enemy overwintering refuge and its interaction with the surrounding landscape. Ecol. Entomol. 21, 155-164.

De La Torre Ugarte, D.G., English, B.C., Jensen, K., 2007. Sixty billion gallons by 2030: Economic and agricultural impacts of ethanol and biodiesel expansion. Am. J. Agr. Econ. 89, 1290-1295.

Egbendewe-Mondzozo, A., Swinton, S., Izaurralde, R., Manowitz, D., Zhang, X., 2011. Biomass supply from alternative cellulosic crops and crop residues: A spatially explicit bioeconomic modeling approach. Biomass Bioenerg. 35, 4636-4647.

Energy Independence and Security Act (EISA), 2007. H.R. 6, 110 US Congress (January 4, 2007).

Epplin, F.M., 1996. Cost to produce and deliver switchgrass biomass to an ethanol-conversion facility in the southern plains of the United States. Biomass Bioenerg, 11, 459 -467.

Fernandez-Cornejo, J., Wechsler, S., 2012. Revisiting the impact of Bt corn adoption by U.S. farmers. Agr. Resource Econ. Rev. 41, 377-390.

Graham, R.L., English, B.C., Noon, C.E., 2000. A geographical information system-based modeling system for evaluating the cost of delivered energy crop and feedstock. Biomass Bioenerg 18, 309-329.

Honek, A. Nitrogen fertilization and abundance of the cereal aphids Metopolophium dirhodum and Sitobion avenae (Homoptera: Aphididae), 1991. J. Plant Dis. Protection. 98, 655-660. 
Howitt, R.E., 1995. Positive mathematical programming. Am. J. Agr. Econ. 77, 329-342.

Kanellopoulos, A., Berentsen, P.B.M., Heckelei, T., Van Ittersum, M.K., Oude Lansink, A.G.J.M., 2010. Assessing the forecasting performance of a generic bio-economic farm model calibrated with two different PMP variants. J. Agr. Econ. 61, 274-294.

Khanna, M., Chen, X., Huang, H., Onal, H., 2011. Supply of cellulosic biofuel feedstocks and regional production pattern. Am. J. Agr. Econ. 93, 473-480.

Lambert, D.K., Middleton J., 2010. Logistical design of a regional herbaceous crop residuebased ethanol production complex. Biomass Bioenerg. 34, 91-100.

Landis, D.A., Gardiner, M.M., van der Werf, W. Swinton, S.M., 2008. Increasing corn for biofuel production reduces biocontrol services in agricultural landscapes. Proc. Natl Acad. Sci. USA $105,20552-20557$.

Lazarus W.F., 2012. Wisconsin, and Indiana custom machine and work rate estimates (20102012) [accessed on February 15, 2013]. Available from: http://faculty.apec.umn.edu/wlazarus/tools.html

Letourneau, D.K., Jedlicka, J.A., Bothwell, S.G., Moreno, C.R., 2009. Effects of natural enemy biodiversity on the suppression of arthropod herbivores in terrestrial ecosystems. Annu. Rev. Ecol. Evol. S. 40, 573-592.

Linn, J., Raeth-Knight, M., 2007. University of Minnesota dairy extension corn silage price analysis. [accessed on February 15, 2013]. Available from: http://www1.extension.umn.edu/dairy/feed-and-nutrition/corn-silage-price-goes-up/

Mapemba, L.D., Epplin, F.M., Huhnke, R.L., Taliaferro, C.M., 2008. Herbaceous plant biomass harvest and delivery cost with harvest segmented by month and number of harvest machines endogenously determined. Biomass Bioenerg. 32, 1016-27

Meehan, T.D., Werling, B.P., Landis, D.A., Gratton, C., 2011. Agricultural landscape simplification and insecticide use in the Midwestern United States. P. Natl. Acad. Sci. USA 108, $11500-11505$.

Meehan, T.D., Werling, B.P., Landis, D.A., Gratton, C., 2012. Pest-suppression potential of Midwest landscapes under contrasting bioenergy scenarios. PLoS one 7, e41728.

Meehan, T.D., Gratton, C., Diehl, E., Hunt, N.D., Mooney, D.F., Ventura, S.J., Barham, B.L., Jackson, R.D., 2013. Ecosystem-Service Tradeoffs Associated with Switching from Annual to Perennial Energy Crops in Riparian Zones of the US Midwest. PloS one 8(11), e80093. 
Nash, S., 2007. Decrypting biofuel scenarios. BioScience 57, 472-477.Searchinger. T., Heimlich, R., Houghton, R.A., Dong, F.X., Elobeid, A., Fabiosa, J., Tokgoz, S., Hayes, D., Yu, T.H., 2008. Use of US croplands for biofuels increases greenhouse gases through emissions from land-use change. Science 319, 1238-1240.

Skevas, T., Stefanou, S. E. and Oude Lansink, A., 2013. Do farmers internalise environmental spillovers of pesticides in production?. J. Agr. Econ. 64, 624-640.

Stein, D., 2012. Crop budget. East Lansing, Michigan State University [accessed on January 20, 2013]. Available from: https://www.msu.edu/ steind/

Tembo, G., Epplin, F.M., Huhnke, L.R., 2003. Integrative investment appraisal of a lignocellulosic biomass-to-ethanol industry. J. Agr. Resour .Econ. 28, 611-633.

Tilman, D., Hill, J., Lehman, C., 2006. Carbon-negative biofuels from low-input high-diversity grassland biomass. Science 314, 1598-1600.

USDA, 2014. United States Department of Agriculture, National agricultural statistics service. NASS agricultural chemical use data. Washington DC: Department of Agriculture [accessed on April 30, 2014]; Available from: http://quickstats.nass.usda.gov/?sector_desc=ENVIRONMENTAL\#DB688ABD-93A5-3E019E09-CFB37228C761.

USDA, 2013. United States Department of Agriculture, National agricultural statistics service. Field crops prices. Washington DC: Department of Agriculture [accessed on January 15, 2013]; Available from: http://www.nass.usda.gov/Data_and_Statistics/index.asp .van Rensburg, J.B.J., 2007. First report of field resistance by stem borer, Busseola fusca (Fuller) to Bt-transgenic maize. S. Afr. J. Plant Soil 24, 147-151.

Walsh, M.E., 2000. Method to estimate bioenergy crop feedstock supply curves. Biomass Bioenerg. 18, 283-289.

Zhang, W., Swinton, S.M., 2012. Optimal control of soybean aphid in the presence of natural enemies and the implied value of their ecosystem services. J, Environ, Management 96, 7-16. 


\section{Tables}

Table 1. Parameters used in the empirical bioeconomic model.

\begin{tabular}{|c|c|c|c|c|}
\hline Parameters & Values & Units & $\begin{array}{l}\text { Commercial } \\
\text { value and } \\
\text { unit }\end{array}$ & Source \\
\hline \multicolumn{5}{|l|}{ Field crop prices } \\
\hline Corn grain & 237 & $\$ / M g$ & $6 \$ / b u$ & $\begin{array}{l}\text { 2010-2012 average from USDA- } \\
\text { NASS }\end{array}$ \\
\hline Soybean & 442 & $\$ / \mathrm{Mg}$ & $12 \$ / b u$ & \\
\hline Wheat & 233 & $\$ / \mathrm{Mg}$ & $6 \$ / b u$ & \\
\hline Alfalfa & 127 & $\$ / M g$ & $116 \$ /$ ton & \\
\hline Canola & 517 & $\$ / M g$ & $23 \$ / \mathrm{cwt}$ & \\
\hline Corn silage & 56 & $\$ / M g$ & $1 \$ / b u$ & $\begin{array}{l}\text { Estimated by authors using the } \\
\text { corn silage price analysis of Linn } \\
\text { and Raeth-Knight (2007) }\end{array}$ \\
\hline \multicolumn{5}{|l|}{ Fertilizer nutrient prices } \\
\hline Nitrogen & 0.62 & $\$ / \mathrm{Lb}$ & & 2010-2012 average from Stein \\
\hline Phosphorus & 0.58 & $\$ / \mathrm{Lb}$ & & \\
\hline Potassium & 0.51 & $\$ / L b$ & & \\
\hline \multicolumn{5}{|c|}{ Land use validation parameters } \\
\hline Corn grain & 78,661 & ha & & $\begin{array}{l}\text { 2010-2012 average from USDA- } \\
\text { NASS }\end{array}$ \\
\hline Soybean & 69,680 & ha & & \\
\hline Wheat & 13,304 & ha & & \\
\hline Alfalfa & 44,712 & ha & & \\
\hline Canola & 0 & ha & & \\
\hline Corn silage & 27,904 & ha & & \\
\hline \multicolumn{5}{|c|}{$\underline{\text { Transport cost parameters }}$} \\
\hline Loading and unloading & g $\quad 3.37$ & $\begin{array}{l}\$ / \mathrm{Mg} \\
\$ / \mathrm{Mg}-\end{array}$ & & \\
\hline Hauling distance cost & 0.09 & $\mathrm{~km}$ & & \\
\hline Hauling time cost & 4.26 & $\$ M g-h$ & & \\
\hline \multicolumn{5}{|c|}{$\underline{\text { Simulated EPIC mean yields }}$} \\
\hline Corn grain & 6.37 & $\mathrm{Mg} / \mathrm{ha}$ & & $\begin{array}{l}1986-2009 \text { average simulated from } \\
\text { EPIC }\end{array}$ \\
\hline Soybean & 2.14 & $\mathrm{Mg} / \mathrm{ha}$ & & \\
\hline Wheat & 3.03 & $\mathrm{Mg} / \mathrm{ha}$ & & \\
\hline Alfalfa & 7.19 & $\mathrm{Mg} / \mathrm{ha}$ & & \\
\hline Canola & 2.09 & $\mathrm{Mg} / \mathrm{ha}$ & & \\
\hline Corn silage & 12.60 & $\mathrm{Mg} / \mathrm{ha}$ & & \\
\hline
\end{tabular}




\begin{tabular}{|c|c|c|c|}
\hline Corn stover & 2.91 & $\mathrm{Mg} / \mathrm{ha}$ & \\
\hline Wheat straw & 2.41 & $\mathrm{Mg} / \mathrm{ha}$ & \\
\hline Switchgrass & 11.58 & $\mathrm{Mg} / \mathrm{ha}$ & \\
\hline Poplar & 8.06 & $\mathrm{Mg} / \mathrm{ha}$ & \\
\hline Miscanthus & 16.75 & $\mathrm{Mg} / \mathrm{ha}$ & \\
\hline $\begin{array}{l}\text { Native praire - cool } \\
\text { season }\end{array}$ & 8.17 & $\mathrm{Mg} / \mathrm{ha}$ & \\
\hline $\begin{array}{l}\text { Native praire - cool } \\
\text { season } \\
\text { Grass mixes of } 5\end{array}$ & 7.73 & $\mathrm{Mg} / \mathrm{ha}$ & \\
\hline types & 10.42 & $\mathrm{Mg} / \mathrm{ha}$ & \\
\hline $\begin{array}{l}\text { Grass mixes of } 6 \\
\text { types }\end{array}$ & 10.81 & $\mathrm{Mg} / \mathrm{ha}$ & \\
\hline $\begin{array}{l}\text { Storage loss } \\
\text { coefficient }\end{array}$ & 88 & $\mathrm{Kg} / \mathrm{Mg}$ & $\begin{array}{l}\text { Obtained from Brechbill et al., } \\
2011\end{array}$ \\
\hline
\end{tabular}


Table 2. Fixed effect estimates from the mixed-effect model.

\begin{tabular}{lll}
\hline Fixed effects & Estimate & SE \\
\hline Field-level variables & & \\
Intercept (Corn as reference) & 0.044 & 0.130 \\
Soybean & 0.080 & 0.124 \\
Switchgrass & 0.420 & 0.124 \\
Diverse grass & 0.252 & 0.056 \\
& & \\
Landscape-level variables & & \\
Grassland landscape proportion & 0.843 & 0.204 \\
Forest landscape proportion & 0.372 & 0.120 \\
\hline
\end{tabular}

Note: The dependent variable is removal rates of corn earworm (Helicoverpa zea) eggs. SE denotes standard error. 
Table 3. Insecticide use data

\begin{tabular}{|c|c|c|c|c|}
\hline Crop & $\begin{array}{l}\text { Most important } \\
\text { insects }\end{array}$ & Insecticide & $\begin{array}{l}\text { Price } \$ / G L \\
(\mathbf{2 0 1 2})\end{array}$ & $\begin{array}{l}\text { Dosage fl. } \\
\text { GL/A }\end{array}$ \\
\hline Corn & $\begin{array}{l}\text { ECB and corn } \\
\text { rootworm }\end{array}$ & - & - & - \\
\hline Wheat & Grain aphids & $\begin{array}{l}\text { lambda-cyhalothrin } \\
\text { (Warrior 2CS) } \\
\text { lambda-cyhalothrin }\end{array}$ & 270.36 & 0.015 \\
\hline Soybeans & soybean aphid & $\begin{array}{l}\text { (Warrior 2CS) } \\
\text { lambda-cyhalothrin }\end{array}$ & 270.36 & 0.013 \\
\hline Alfalfa & Potato leafhopper & (Warrior 2CS) & 270.36 & 0.013 \\
\hline
\end{tabular}




\section{Figures}
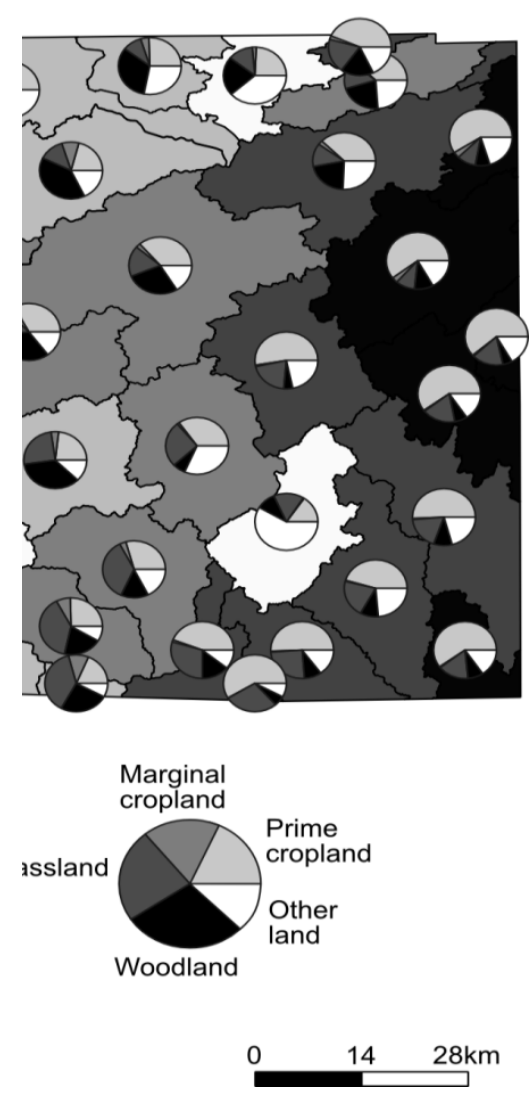

Figure 1. Landscape proportions per land unit. 


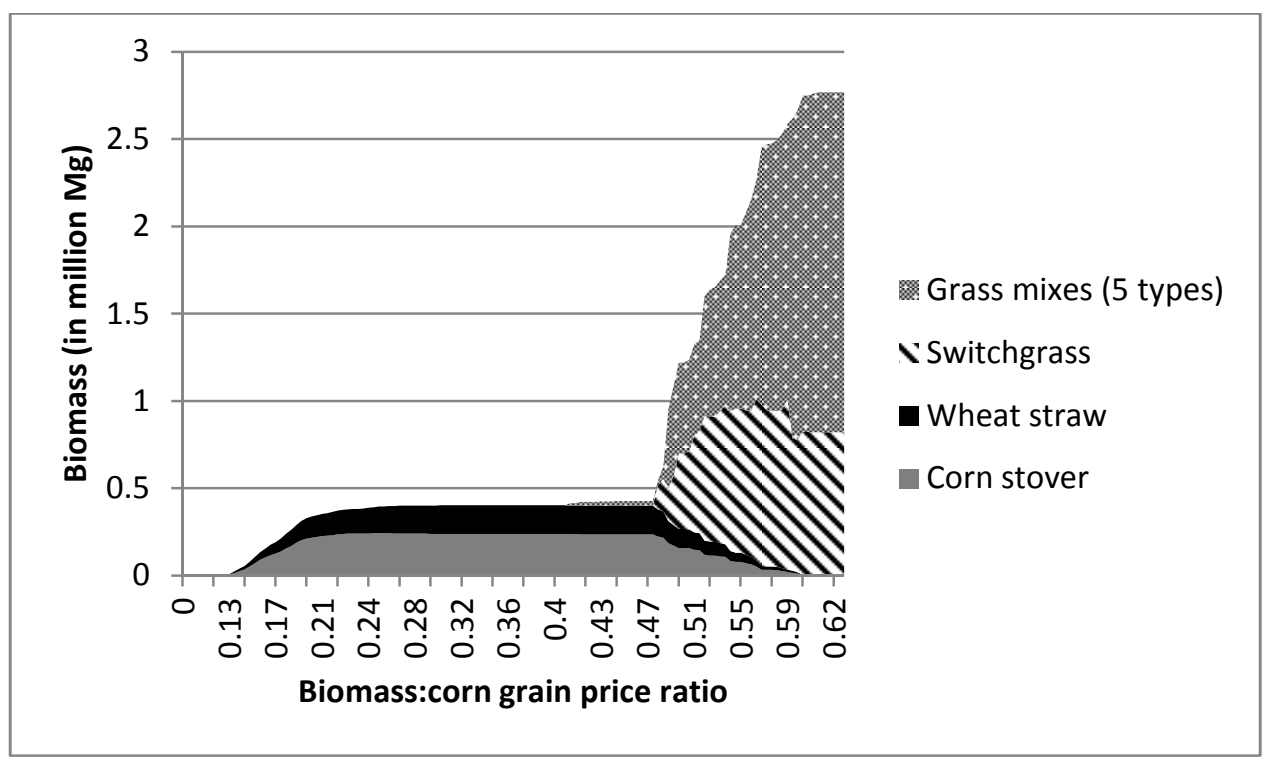

Figure 2. Predicted biomass production as function of biomass:corn grain price ratio in the four county area of Wisconsin, USA. 


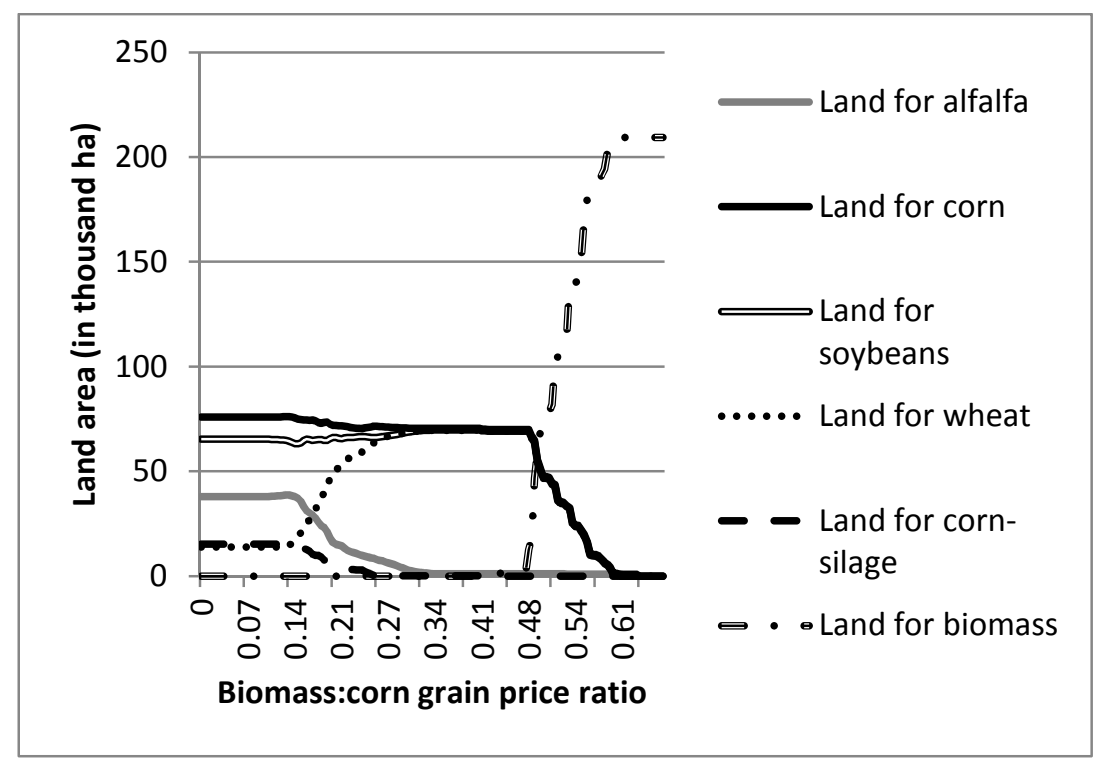

Figure 3. Predicted land use change as function of biomass:corn grain price ratio in the four county area of Wisconsin, USA. 


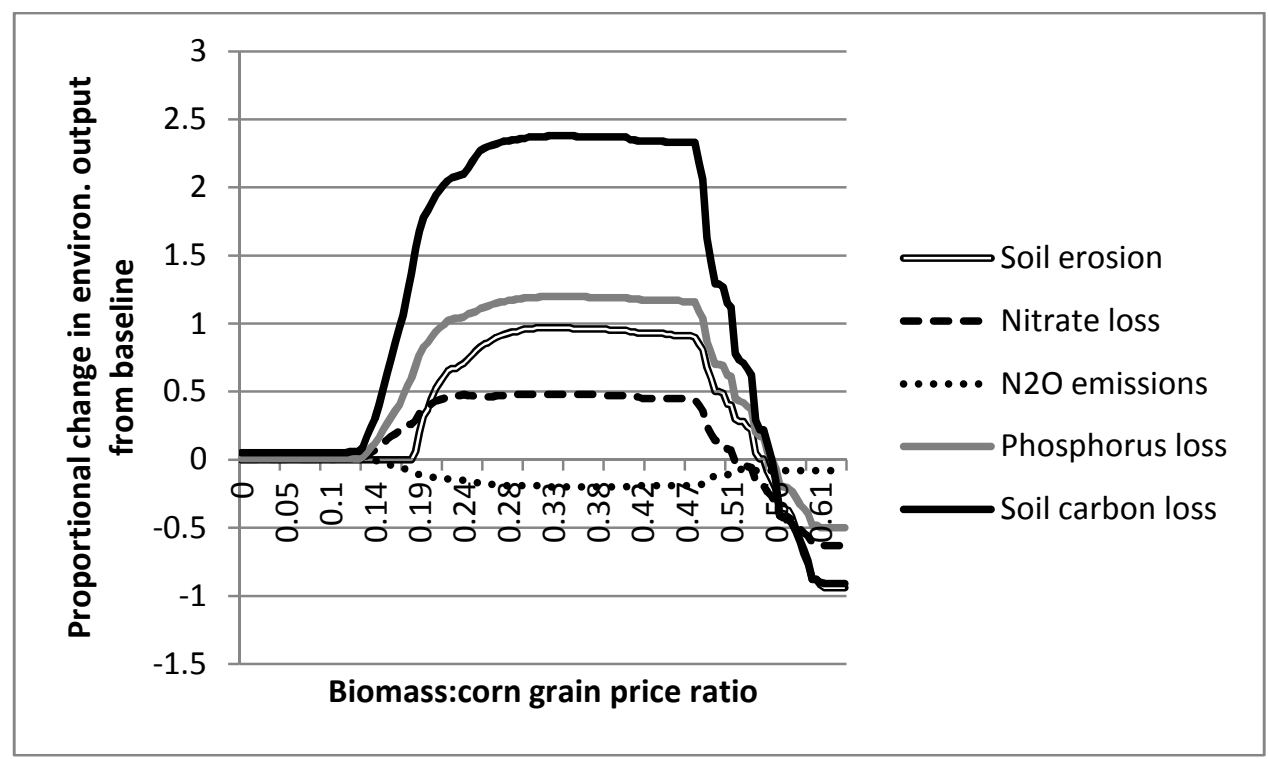

Figure 4. Change in environmental outputs level from baseline of no biomass production as biomass:corn grain price ratio increases in the four county area of Wisconsin, USA. 


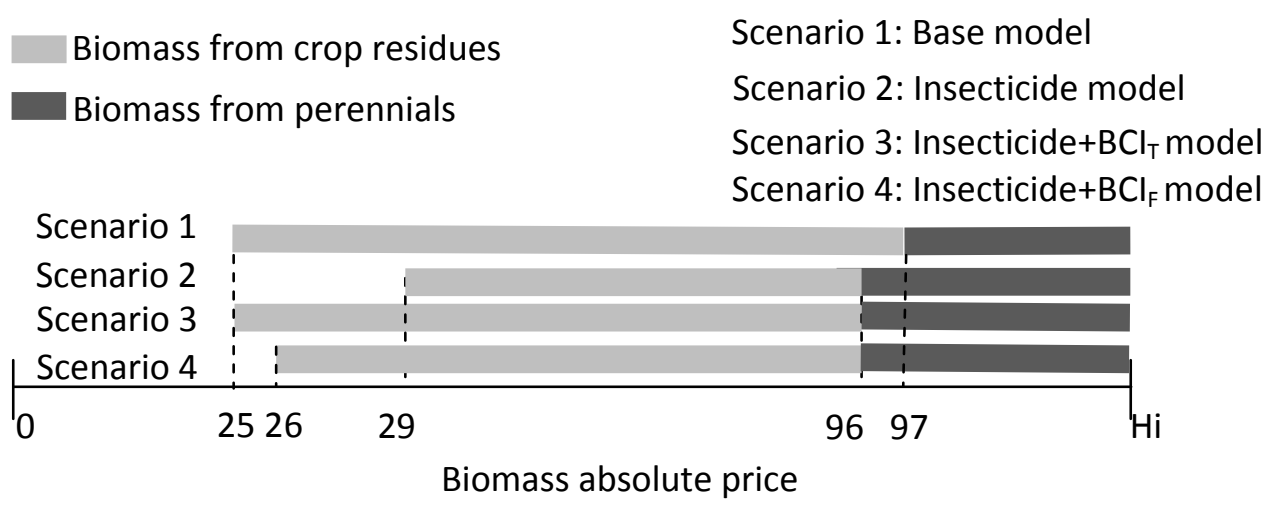

Figure 5. Minimum biomass supply price (i.e., biomass:corn grain price ratio in $\$ / \mathrm{dry} \mathrm{Mg}$ ) for crop residues and perennial crops across the different modeling scenarios.

Note: The "Base model" stands for the initial bioeconomic model used to analyze biomass production from crop residues and cellulosic crops, the "Insecticide model" stands for the model that is adjusted for insecticide use, the "Insecticide+BCI $\mathrm{B}_{\mathrm{T}}$ model" stands for the model that is adjusted for insecticide use and accounts for total agricultural pest biocontrol $\left(\mathrm{BCI}_{\mathrm{T}}\right)$, and the "Insecticide+ $\mathrm{BCI}_{\mathrm{F}}$ model" stands for the model that accounts for insecticide use and for only the within crop system agricultural pest biocontrol $\left(\mathrm{BCI}_{\mathrm{F}}\right)$. 


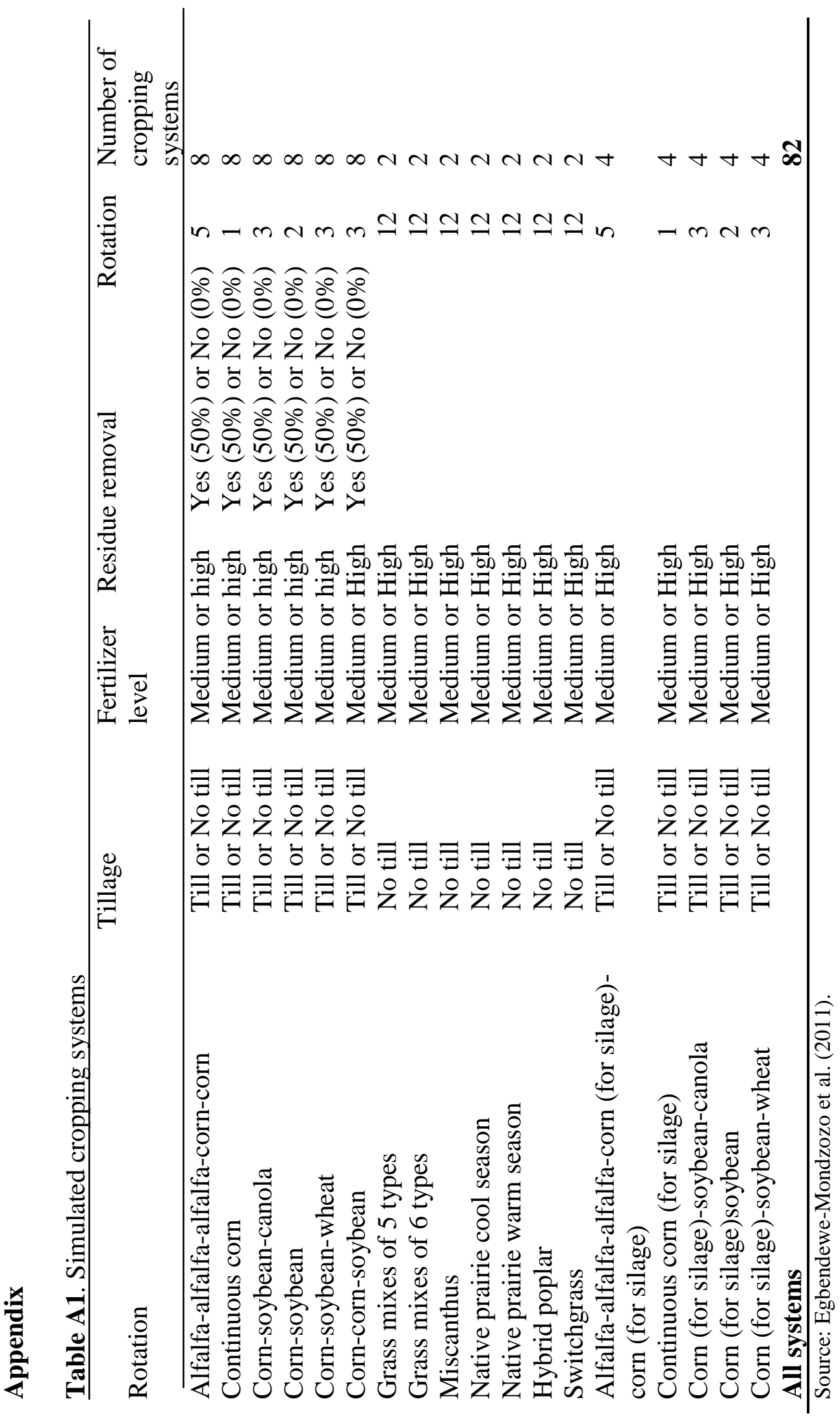


Table A2. Model parameters and variables definition

\begin{tabular}{|c|c|}
\hline $\begin{array}{l}\text { Parameters, sets } \\
\text { and variables }\end{array}$ & Definition \\
\hline \multicolumn{2}{|l|}{$\underline{\text { Sets }}$} \\
\hline$h$ & Set of nine biomass outputs studied in the model \\
\hline$i$ & Set of 80 sub-watersheds with good or poor land quality \\
\hline$j$ & Set of 82 cropping systems simulated on each sub-watershed \\
\hline$l$ & Set of three fertilizer nutrients used in the cropping systems \\
\hline$n$ & Set of five environmental outputs from cropping systems \\
\hline$s$ & Set of 15 traditional and biomass crop products combined \\
\hline \multicolumn{2}{|l|}{$\underline{\text { Parameters }}$} \\
\hline$a_{i j s}$ & Yield of crop s from land parcel $i$ and cropping system $j$ \\
\hline$b_{i}$ & Maximum quantity of cropland available in sub-watershed i \\
\hline$c_{j}$ & Average cost of production from cropping system $j$ \\
\hline$e_{n j}$ & Level of environmental output $n$ in cropping system $j$ \\
\hline$o_{l j}$ & Quantity per ha of fertilizer nutrient 1 used in cropping system $j$ \\
\hline$p_{s}$ & Market price of crop s \\
\hline$r_{l}$ & Unit cost of fertilizer nutrient 1 \\
\hline$\emptyset_{s}$ & Storage loss coefficient for biomass products \\
\hline$\rho_{s}$ & Average base yield in the calibration of the output product s \\
\hline$\delta_{s}$ & $\begin{array}{l}\text { Average linear yield decline with increasing land allocated to } \\
\text { output product s }\end{array}$ \\
\hline$\Gamma_{\pi}$ & Quantity limit of environmental outputs allowed \\
\hline \multicolumn{2}{|l|}{$\underline{\text { Variables }}$} \\
\hline$T C_{h}$ & Cost of transporting biomass product $\mathrm{h}$ to the demand point \\
\hline$\Psi$ & Total quantity of all biomass produced in the region \\
\hline$x_{i j}$ & $\begin{array}{l}\text { Quantity of land in sub-watershed i allocated to cropping system } \\
\mathrm{j}\end{array}$ \\
\hline$w_{j}$ & Actual insecticide cost of cropping system $\mathrm{j}$ \\
\hline $\bar{w}_{j}$ & Adjusted insecticide cost of cropping system $j$ \\
\hline
\end{tabular}

Source: Egbendewe-Mondzozo et al., 2011 